\title{
Palmitoleic Acid Calcium Salt: A Lubricant and Bactericidal Powder from Natural Lipids
}

\author{
Yoshiaki Yamamoto ${ }^{1}$, Yuki Kawamura ${ }^{1}$, Yuki Yamazaki ${ }^{1}$, Tatsuro Kijima ${ }^{1}$, \\ Toshiya Morikawa ${ }^{2}$ and Yoshimune Nonomura ${ }^{1 *}$ \\ ${ }^{1}$ Department of Biochemical Engineering, Graduate School of Science and Engineering, Yamagata University (4-3-16 Jonan, Yonezawa \\ 992-8510, JAPAN) \\ ${ }^{2}$ Skin-beauty Laboratories, Kao Corporation (2-1-3, Bunka, Sumida-ku, Tokyo 131-8501, JAPAN)
}

\begin{abstract}
Palmitoleic acid is a promising bactericidal agent for cleansing products with alternative bactericidal abilities. In this study, we focus on the physical and biological activity of palmitoleic acid calcium salt (C16:1 fatty acid Ca salt) because it forms via an ion-exchange reaction between palmitoleic acid and $\mathrm{Ca}$ ions in tap water, and remains on the skin surface during the cleansing process. Here, we prepared C16:1 fatty acid Ca salt to investigate its crystal structure and physical and bactericidal properties. The Ca salt was a plate-shaped lamellar crystalline powder with a particle diameter of several micrometers to several tens of micrometers; it exhibited significant lubricity and alternative bactericidal activity against Staphylococcus aureus (S. aureus) and Propionibacterium acnes (P. acnes). We also examined other fatty acid Ca salts prepared from lauric acid (C12:0 fatty acid), palmitic acid (C16:0 fatty acid), and oleic acid (C18:1 fatty acid). The bactericidal activities and lubricity of the fatty acid Ca salts changed with the alkyl chain length and the degree of unsaturation. The C16:1 fatty acid Ca salt exhibited the strongest selective bactericidal ability among the four investigated fatty acid Ca salts. These findings suggest that C16:1 fatty acid and its Ca salt have potential applications in cleansing and cosmetic products.
\end{abstract}

Key words: palmitoleic acid, fatty acid calcium salt, crystal structure, friction property, bactericidal ability

\section{INTRODUCTION}

Palmitoleic acid (C16:1 fatty acid), which is contained in plant oils from macadamia nuts ${ }^{1)}$, hazel nuts ${ }^{2}$, and seabuckthorn $^{3)}$ and in the sebum cutaneum of humans ${ }^{4)}$, exhibits antibacterial activities and bactericidal properties toward S. aureus, Streptococcus salivarius, the anaerobe Fusobacterium nucleatum, Neisseria gonorrhea, and Helicobacter pylori ${ }^{5-8)}$. This fatty acid has great potential as a bactericidal agent for cleansing products because its activity is selective: although this fatty acid exhibits strong bactericidal activity toward some harmful bacteria, as previously mentioned, it does not kill good bacterium such as S. epidermidis. Some previous studies have shown that maintaining good bacteria on skin surfaces is beneficial because they play important roles in maintaining healthy conditions $^{9,10)}$.

When C16:1 fatty acids are used as ingredients in cleansing and cosmetic products, the physical and bactericidal properties of C16:1 fatty acid Ca salt are curious because hydrogen ions in fatty acid molecules are exchanged for $\mathrm{Ca}$ ions in tap water ${ }^{11-13)}$. This exchange with a divalent metal ion can induce a catastrophic decrease in the bactericidal properties of fatty acids via insolubilization of their molecules in water. However, the exchange with Ca ions might also bring some benefits as a cosmetic ingredient. Many surfactant divalent metal salts with lamellar crystalline structures have been used in cosmetic and medical products because these fluid powders exhibit both hydrophobicity and lubricating ability ${ }^{14-16)}$.

In this study, we investigated the crystal structure, lubricity, and bactericidal properties of a C16:1 fatty acid Ca salt prepared by an ion-exchange reaction. The bactericidal activities of the fatty acid Ca salt against $S$. aureus, S. epidermidis, and $P$. acnes, among the many bacteria found on the surface of human skin, were evaluated because these bacteria are associated with skin damage and acne ${ }^{17,}$ 18). We also examined other fatty acid Ca salts prepared from lauric acid (C12:0 fatty acid), palmitic acid (C16:0 fatty acid), and oleic acid (C18:1 fatty acid) to demonstrate the effect of the alkyl chain length and the degree of unsat-

\footnotetext{
*Correspondence to: Yoshimune Nonomura, Department of Biochemical Engineering, Graduate School of Science and Engineering, Yamagata University, 4-3-16 Jonan, Yonezawa 992-8510, JAPAN

E-mail: nonoy@yz.yamagata-u.ac.jp

Accepted October 23, 2014 (received for review August 9, 2014)

Journal of Oleo Science ISSN 1345-8957 print / ISSN 1347-3352 online

http://www.jstage.jst.go.jp/browse/jos/ http://mc.manusriptcentral.com/jjocs
} 


\section{Y. Yamamoto, Y. Kawamura, Y. Yamazaki et al.}

uration on the bactericidal activities of the fatty acid Ca salts. Unsaturated carbon bonds in an alkyl chain are known to change the physical and bactericidal properties of fatty acids ${ }^{19-21)}$.

\section{EXPERIMENTAL PROCEDURES}

\subsection{Materials}

Palmitoleic acid $\left(\mathrm{CH}_{3}\left(\mathrm{CH}_{2}\right)_{5} \mathrm{CH}=\mathrm{CH}\left(\mathrm{CH}_{2}\right)_{7} \mathrm{COOH}, \mathrm{C} 16: 1\right.$ fatty acid), lauric acid $\left(\mathrm{CH}_{3}\left(\mathrm{CH}_{2}\right)_{10} \mathrm{COOH}, \mathrm{C} 12: 0\right.$ fatty acid), and oleic acid $\left(\mathrm{CH}_{3}\left(\mathrm{CH}_{2}\right)_{7} \mathrm{CH}=\mathrm{CH}\left(\mathrm{CH}_{2}\right)_{7} \mathrm{COOH}\right.$, C18:1 fatty acid) were purchased from Wako Pure Chemical Industries, Ltd. (Osaka, Japan). Palmitic acid $\left(\mathrm{CH}_{3}\left(\mathrm{CH}_{2}\right)_{14}\right.$ $\mathrm{COOH}, \mathrm{C16:0}$ fatty acid) and calcium chloride dihydrate were purchased from Sigma-Aldrich Co. LLC (St. Louis, USA). Sodium hydroxide was purchased from Kanto Chemical Co., Inc. (Kanagawa, Japan).

\subsection{Preparation}

The C16:1 fatty acid $(0.01 \mathrm{~mol})$ in the liquid state was mixed with $100 \mathrm{~mL}$ of 50wt\% aqueous ethanol. Sodium hydroxide $(0.01 \mathrm{~mol})$ in $2 \mathrm{~g}$ of water and calcium chloride dihydrate $(0.0055 \mathrm{~mol})$ in $5.0 \mathrm{~g}$ of $50 \mathrm{wt} \%$ aqueous ethanol were added to the C16:1 fatty acid aqueous ethanol solution. The turbid solution was filtered to obtain the white precipitate. The precipitate was washed with water and acetone to remove unreacted C16:1 fatty acid and calcium chloride and was subsequently dried under reduced pressure. If the powder is assumed to be a monohydrate containing two fatty acid molecules and a calcium ion, the experimental values are consistent with the calculated values. Melting point: $134.7-141.5^{\circ} \mathrm{C}$. Anal. Found: C, 67.78 ; H, 10.85; Ca, 6.59. Calcd for $\mathrm{Ca}\left(\mathrm{C}_{7} \mathrm{H}_{14}=\mathrm{C}_{8} \mathrm{H}_{15} \mathrm{COO}\right)_{2} \cdot \mathrm{H}_{2} \mathrm{O}$ : C, 67.61; H, 10.56; O, 14.08; Ca, 7.04\%. ${ }^{1} \mathrm{H}$ NMR (500 MHz, DMSO- $d_{6}$, and THF- $\left.d_{8}\right) \delta(\mathrm{ppm}) 0.84(\mathrm{~m}, 6 \mathrm{H}), 1.24(\mathrm{~m}, 32 \mathrm{H})$, $1.46(\mathrm{~m}, 4 \mathrm{H}), 1.97(\mathrm{~m}, 8 \mathrm{H}), 2.08(\mathrm{t}, J=7.5,4 \mathrm{H})$, and $5.31(\mathrm{t}$, $J=4.5,4 \mathrm{H})$. Solubility in water and ethanol was $1.2 \times 10^{-5}$ mol L ${ }^{-1}$ and $8.4 \times 10^{-3} \mathrm{~mol} \mathrm{~L}^{-1}$, respectively. The composition of some already known fatty acid Ca salts containing C12:0 fatty acid, C16:0 fatty acid, and C18:1 fatty acid was checked by elemental analysis: C12:0 fatty acid Ca salt, Anal. Found: C, 62.93; H, 10.27; Ca, 8.60\%. Calcd for Ca $\left(\mathrm{C}_{11} \mathrm{H}_{23} \mathrm{COO}\right)_{2} \cdot \mathrm{H}_{2} \mathrm{O}$ : C, 63.06; H, 10.05; O, 17.52; Ca, 8.78\%. C16:0 fatty acid Ca salt, Anal. Found: C, 67.45; H, 11.31; $\mathrm{Ca}, 7.05 \%$. Calcd for $\mathrm{Ca}\left(\mathrm{C}_{15} \mathrm{H}_{31} \mathrm{COO}\right)_{2} \cdot \mathrm{H}_{2} \mathrm{O}: \mathrm{C}, 67.05 ; \mathrm{H}$, 11.25; O, 14.06; Ca, 7.05\%. C18:1 fatty acid Ca salt, Anal. Found: C, 69.59; H, 11.22; Ca, 6.27\%. Calcd for $\mathrm{Ca}\left(\mathrm{C}_{9} \mathrm{H}_{8}=\right.$ $\left.\mathrm{C}_{8} \mathrm{H}_{15} \mathrm{COO}\right)_{2} \cdot \mathrm{H}_{2} \mathrm{O}$ : C, 69.68; H, 10.97; O, 12.90; Ca, $6.45 \%$.

\subsection{Characterization}

The calcium content in the obtained powder was investigated using an EDXL300 X-ray fluorescence spectrometer (Rigaku Tokyo, Japan). The melting point was measured using a melting-point determination apparatus (Bibby Scientific, Ltd., Staffordshire, United Kingdom). ${ }^{1} \mathrm{H}$ NMR spectra were recorded on Varian INOVA 500 spectrometers (Agilent Technologies, California, USA). All chemical shifts are stated relative to deuterated solvent signals; the chemical shifts $(\delta)$ are reported in ppm, and the coupling constants $(J)$ are reported in hertz. Scanning electron microscopy (SEM) images were obtained on a SU8000 scanning electron microscope (Hitachi High-Technologies Corp., Tokyo, Japan) using an electron beam accelerating voltage of $1 \mathrm{kV}$. For the X-ray diffraction (XRD) analyses, a MiniFlex X-ray diffractometer (Rigaku, Tokyo, Japan) was operated at $30 \mathrm{kV}$ and $15 \mathrm{~mA}$ to generate $\mathrm{Cu}-\mathrm{K} \alpha$ X-rays.

\subsection{Friction measurement}

Friction measurements were conducted using a friction evaluation meter(Tribo Master TL201Ts, Trinity Lab, Inc., Tokyo, Japan). The meter's specifications are as follows: vertical load: $0.29 \mathrm{~N}$; sliding velocity: $80 \mathrm{~mm} \mathrm{~s}^{-1}$; measurement distance: $30 \mathrm{~mm}$; driving motor: AC servomotor. We evaluated the frictional force when the powder in a $10 \mathrm{~mm}$ $\times 50 \mathrm{~mm} \times 1 \mathrm{~mm}$ hole on SK-050-20 silicone rubber (SKElectronics Co., Ltd., Tokyo, Japan) was rubbed with a polyurethane contact probe that reflects the geometric properties of human fingers. On the probe surface, 29 grooves with a depth of $0.15 \mathrm{~mm}$ were carved at intervals of $0.5 \mathrm{~mm}^{22)}$.

\subsection{Bioactive property}

Bactericidal activities of the fatty acid Ca salts were evaluated for $S$. aureus, $S$. epidermidis, and P. acnes. Fatty acid Ca salts dispersed in 2wt\% aqueous ethanol were added to $10 \mathrm{~mL}$ of $50 \mathrm{mM}$ phosphate buffer $(\mathrm{pH} 6)$ containing bacteria. The concentration of the fatty acid $\mathrm{Ca}$ salts was $100 \mathrm{ppm}$. Bacteria counts per $\mathrm{mL}$ in the initial state were $5.5 \pm 0.3 \log$ colony forming units (CFU). These dispersions were spread onto SCDLP agar gel plates, and the temporal change in the number of bacteria was counted for $24 \mathrm{~h}$.

\section{RESULTS AND DISCUSSION}

\subsection{Preparation of C16:1 fatty acid Ca salt}

The C16:1 fatty acid Ca salt is a white powder that exhibits fluidity and hydrophobicity. When $0.01 \mathrm{~g}$ of the Ca salt was added to $35 \mathrm{~g}$ of water in a screw-cap tube with a diameter of $20.3 \mathrm{~mm}$, the powder particles floated and remained on the surface of the water for more than one month. As shown in Fig. 1, this powder consisted of plateshaped particles with diameters of several micrometers to several tens of micrometers. As mentioned in the experimental section, elemental analyses suggested that this powder contains twice as many moles of C16:1 fatty acid 


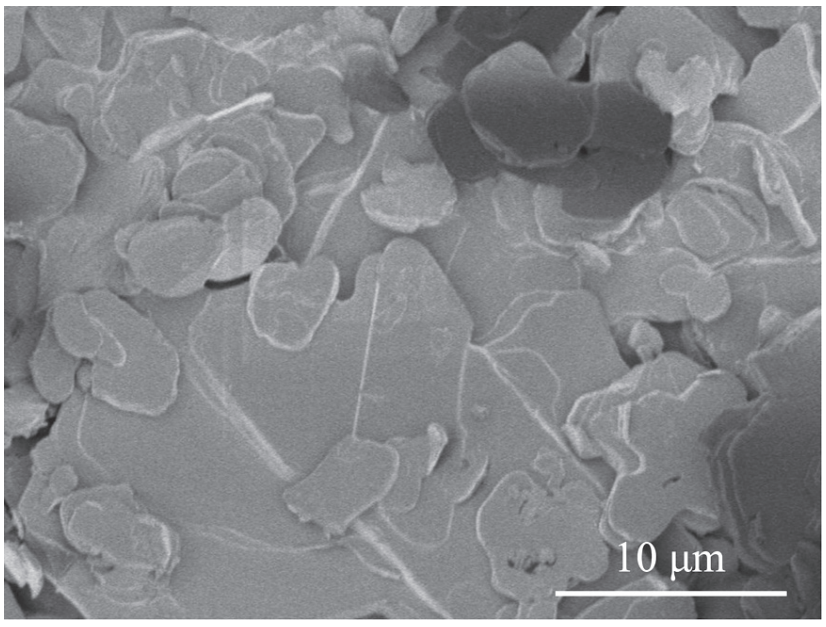

Fig. 1 SEM image of C16:1 fatty acid Ca salt.

molecules as moles of $\mathrm{Ca}$ ions. This ratio between the fatty acid molecules and $\mathrm{Ca}$ ions is similar to that of a C12:0 fatty acid $\mathrm{Ca}$ salt $^{23-26)}$. The appearance and odor did not change even after storage for more than one month at $25^{\circ} \mathrm{C}$ and $50 \%$ relative humidity.

\subsection{Crystal structure of $\mathrm{C} 16: 1$ fatty acid Ca salt}

The XRD profiles for the C16:1 fatty acid Ca salt are shown in Fig. 2. These profiles suggest that the particles are in a lamellar crystalline state. The peaks at $2 \theta=2.1^{\circ}(d$ $=40 \AA), 4.1^{\circ}(d=21 \AA), 6.1^{\circ}(d=15 \AA)$, and $8.1^{\circ}(d=11$ $\AA)$ correspond to the $\left(\begin{array}{lll}1 & 0 & 0\end{array}\right),\left(\begin{array}{lll}2 & 0 & 0\end{array}\right),\left(\begin{array}{lll}3 & 0 & 0\end{array}\right)$, and (4 000$)$ diffractions of bilayer structures, respectively, whereas the peaks between $2 \theta=15^{\circ}$ and $45^{\circ}$ correspond to the two-dimensional lattice spacing of subcells. These patterns are similar to the previous data reported for the C18:0 fatty acid Ca salt and C18:1 fatty acid Ca salt ${ }^{23,24)}$. The separation of ( $\left.\begin{array}{lll}1 & 0 & 0\end{array}\right)$ faces in the case of the C16:1 fatty acid Ca salt was 1-3 $\AA$ shorter than that of the C16:0 fatty acid Ca salt, which is a saturated fatty acid with a similar alkyl length; i.e., $40 \AA$ separation for the C16:1 fatty acid Ca salt and $41 \AA$ separation for the C16:0 fatty acid Ca salt. Moreover, the separation was $5 \AA$ shorter than that of the C18:1 fatty acid Ca salt, which is an unsaturated fatty acid with a longer alkyl length: e.g., $45 \AA$ separation for the C18:1 fatty acid Ca salt. These results suggest that the C16:1 fatty acid Ca salt forms lamellar layers that are similar to those of saturated fatty acid Ca salts and other mono-unsaturated fatty acid Ca salts.

\subsection{Lubricant properties of C16:1 fatty acid Ca salt}

The C16:1 fatty acid Ca salt exhibited remarkable lubricity when the powder was rubbed with a finger model made of urethane rubber onto a silicone rubber plate. During the rubbing process of the Ca salt at a sliding velocity of $80 \mathrm{~mm}$ $\mathrm{s}^{-1}$ and a vertical force of $0.29 \mathrm{~N}$, the dynamic friction coefficient was approximately $0.19 \pm 0.05$, which was 15 times

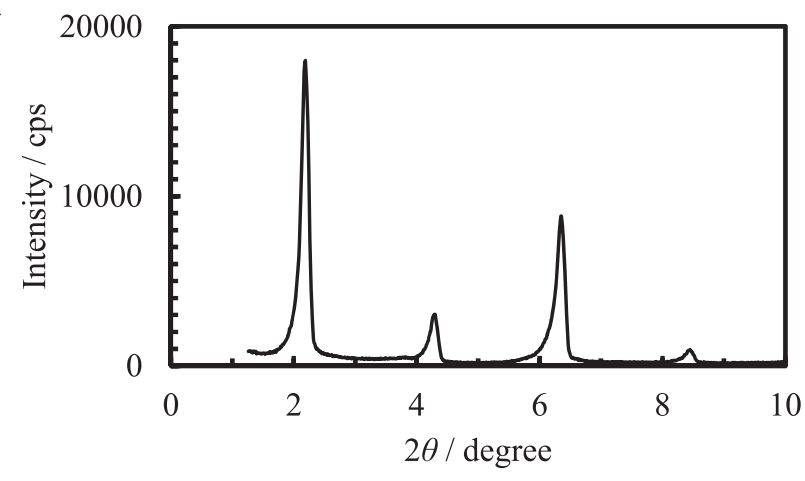

b

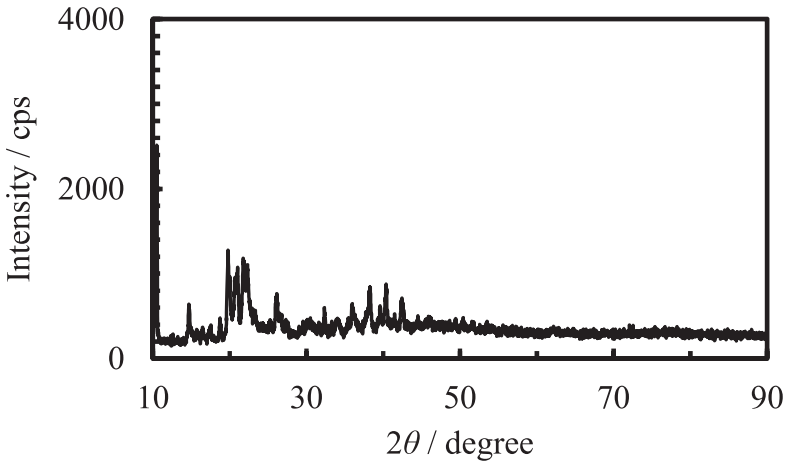

Fig. 2 XRD patterns of C16:1 fatty acid Ca salt: (a) low angle; (b) high angle.

less than that of naked silicone rubber (Fig. 3). This lubricity is similar to that of other fatty acid Ca salts, i.e., $0.24 \pm$ 0.05 (C12:0 fatty acid Ca salt), 0.20 \pm 0.05 (C16:0 fatty acid Ca salt), and 0.19 \pm 0.05 (C18:1 fatty acid Ca salt). These lubrication abilities are more remarkable than those of free fatty acid powders. Under similar conditions, the friction coefficients were $0.77 \pm 0.08$ and $0.85 \pm 0.13$ for the $\mathrm{C} 12: 0$ fatty acid and the C16:0 fatty acid, respectively. The lubricity of surfactant divalent metal salts, including the C16:1 fatty acid Ca salt, is determined by three factors. The first and second factors are cleavage of the lamellar layers and disintegration of the powder aggregates ${ }^{15,16)}$. These disruptions in the structural systems can absorb the friction force between solid surfaces. The third factor is the low surface energy of the fatty acid Ca salts. The adhesion energy between solid particles decreases with increasing hydrophobicity of the surfaces. Previously, we reported that one of surfactant divalent metal salts, $N$-lauroyl taurate Ca salt, forms a thin layer due to the cleavage and disintegration, although the lamellar structure still remained after the deformation ${ }^{15,16)}$. The thin layer was hydrophobic: a water droplet formed a spherical lens on the layer.

\subsection{Bactericidal properties of C16:1 fatty acid Ca salt}

The C16:1 fatty acid Ca salt exhibited the strongest selective bactericidal ability among the four investigated fatty acid Ca salts. The temporal changes for three bacteria are shown in Fig. 4. When the C16:1 fatty acid Ca salt was 


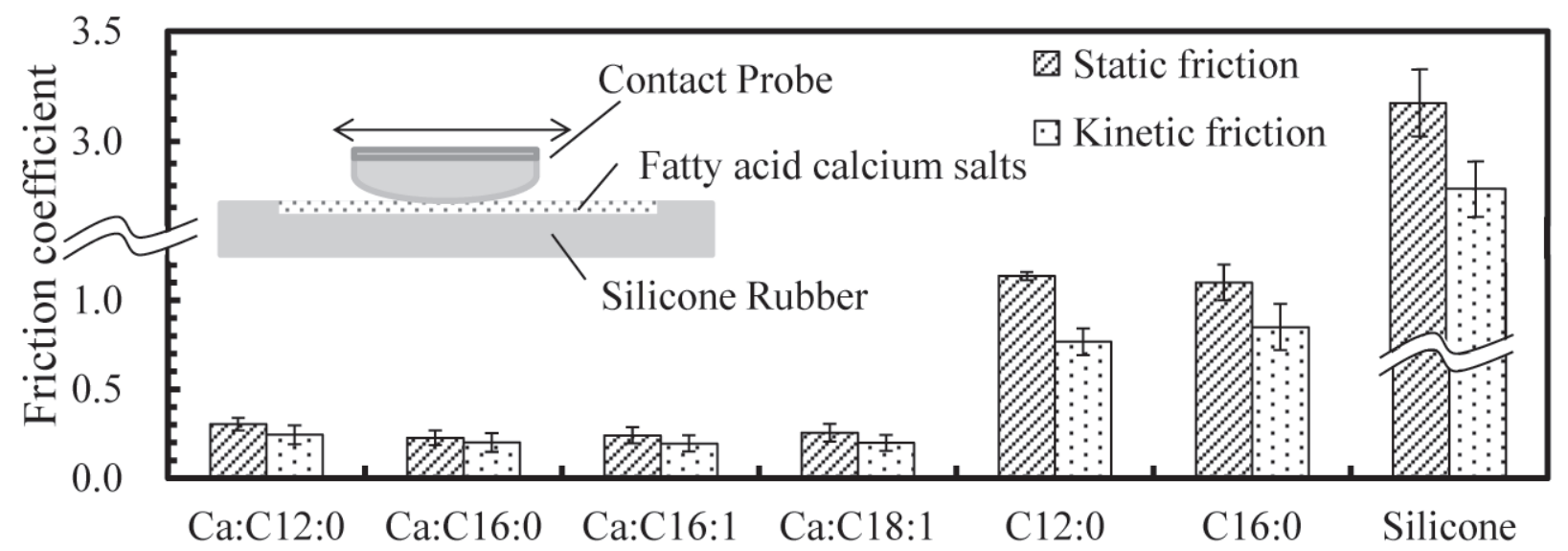

Fig. 3 Friction coefficients of the fatty acid Ca salts, free fatty acids, and silicone substrate.

added to phosphate buffer containing $S$. aureus and $P$. acnes, $5.4 \pm 0.3 \log \mathrm{CFU} \mathrm{mL} \mathrm{m}^{-1}$ of bacteria were reduced to $<1 \log \mathrm{CFU} \mathrm{mL}^{-1}$ after 3 and $24 \mathrm{~h}$, respectively. In the case of $S$. epidermidis, $3.5 \pm 0.5 \log \mathrm{CFU} \mathrm{mL}^{-1}$ of bacteria remained after $24 \mathrm{~h}$. Although the C12:0 fatty acid Ca salt exhibited significant bactericidal ability, the killing speed was slower than that of the C16:1 fatty acid Ca salt. When the C12:0 fatty acid Ca salt was added to phosphate buffer containing $S$. aureus, the bacteria were reduced to $<1 \log$ CFU mL ${ }^{-1}$ after $24 \mathrm{~h}$. In the case of $P$. acnes, $0.8 \pm 1.4 \mathrm{log}$ $\mathrm{CFU} \mathrm{mL}^{-1}$ bacteria remained, and the number of $S$. epidermidis did not decrease significantly. The C18:1 fatty acid Ca salt exhibited weak bactericidal ability only for $P$. acnes; when it was added to phosphate buffer containing $P$. acnes, the number of bacteria decreased to $1.1 \pm 2.0 \mathrm{log}$ $\mathrm{CFU} \mathrm{mL}^{-1}$. The $\mathrm{C16}$ :0 fatty acid Ca salt did not exhibit bactericidal ability toward any of the investigated bacteria. Interestingly, in many cases, a significant difference was not observed between free fatty acids and fatty acid Ca salts with respect to bactericidal activity toward $P$. acnes. The temporal changes in the number of $P$. acnes of fatty acids are shown in Fig. 5.

To our knowledge, this work represents the first report demonstrating selective bactericidal ability of powdery fatty acid Ca salts. We speculate that a small amount of fatty acid dissolved from the Ca salt is the active material that exhibits bactericidal activity. The solubility of the C16:1 fatty acid Ca salt in water was $1.2 \times 10^{-5} \mathrm{~mol} \mathrm{~L}^{-1}$, which was sufficient to show bactericidal activity toward $S$. aureus. Our additional experiments showed that $1 \mathrm{ppm}$ of free C16:1 fatty acid exhibited the ability in 2wt\% aqueous ethanol to reduce the bacteria count from $5.91 \mathrm{log} \mathrm{CFU} \mathrm{mL}^{-1}$ to $4.82,2.08$, and $<1 \log \mathrm{CFU} \mathrm{mL}{ }^{-1}$ at 1,3 , and $24 \mathrm{~h}$ after addition of the C16:1 fatty acid dispersion, respectively. At present, the origin of the strong bactericidal ability of the C16:1 fatty acid Ca salt is unclear. However, the unsaturated site in this fatty acid molecule can contribute to the advancement of the bactericidal ability because the bulky un- saturated alkyl chain increases the fluidity and instability of the cell membrane when the molecule is adsorbed onto the bacterial surface ${ }^{27,28)}$. In addition, the hydrophobicity of C16:1 fatty acid might be suitable for bactericidal agent to $S$. aureus and $P$. acnes. Previous studies on pharmaceuticals reported that the lipophilic character of organic compounds is one of the important factors for drug activity ${ }^{29)}$. For example, antibacterial activity of long-chain fatty alcohols against $S$. aureus varied with the length of the aliphatic carbon chain ${ }^{30)}$. The amount of absorption on bacteria surface and membrane damaging ability of C16:1 fatty acid $\mathrm{Ca}$ salt will be evaluated to explain the bactericidal ability of these fatty acid Ca salts.

\section{CONCLUSIONS}

C16:1 fatty acid Ca salt is a plate-shaped lamellar crystalline powder with a particle diameter of several micrometers to several tens of micrometers. This Ca salt is potentially a powerful cosmetic material because the powder exhibits lubricity similar to that of the C12:0 fatty acid Ca salt, which is currently used as a solid lubricant in the cosmetics industry. Such a lubricant material contributes to an improved tactile feeling of skin-surface and powdery cosmetic products. The powder also exhibits alternative bactericidal activity toward $S$. aureus and $P$. acnes, even though very little of this Ca salt can dissolve in aqueous media. The selective bactericidal ability of C16:1 fatty acid Ca salt is a suitable property for the ingredient of cosmetic products because higher bactericidal activity for all bacteria is not always better for human skin. These bactericidal powder particles possibly exhibit a lasting bactericidal effect on the skin surface. Toward the practical application of C16:1 fatty acid and its Ca salt, the formation and adsorption of C16:1 fatty acid Ca salt should be investigated further, as should its bactericidal properties on the skin surface, its safety, and its stability. In addition, further investigation to 
$\mathbf{a}$

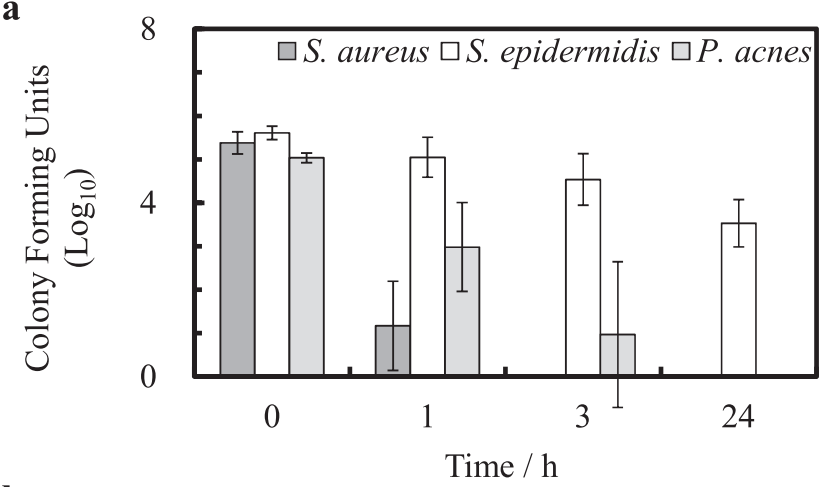

b

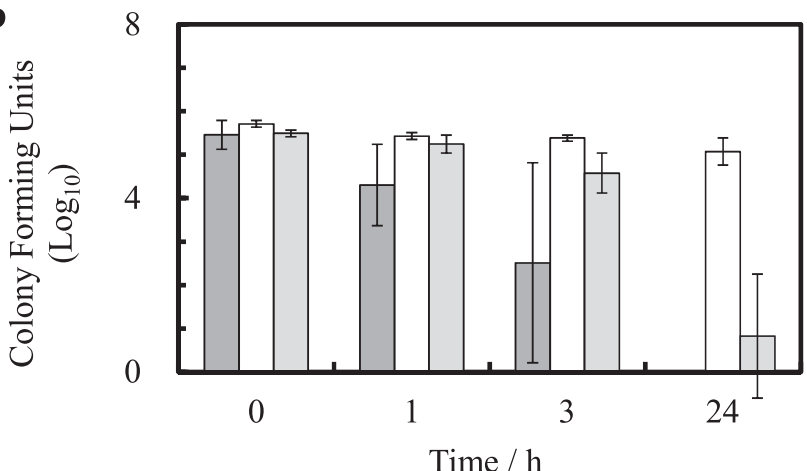

c

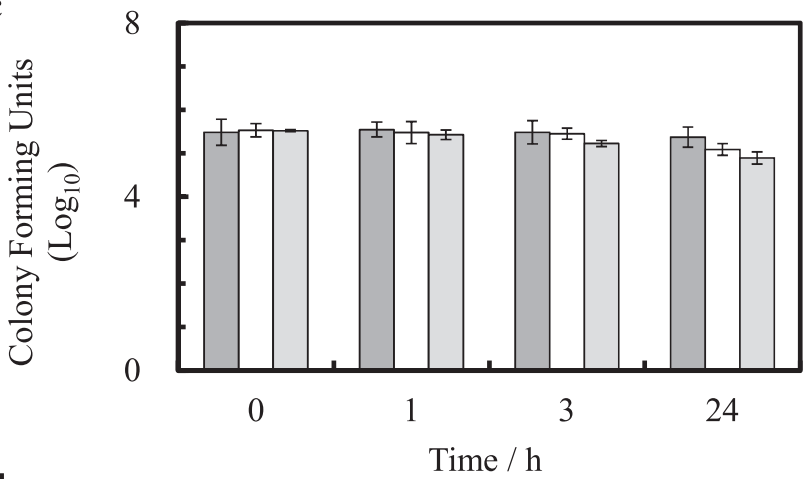

d

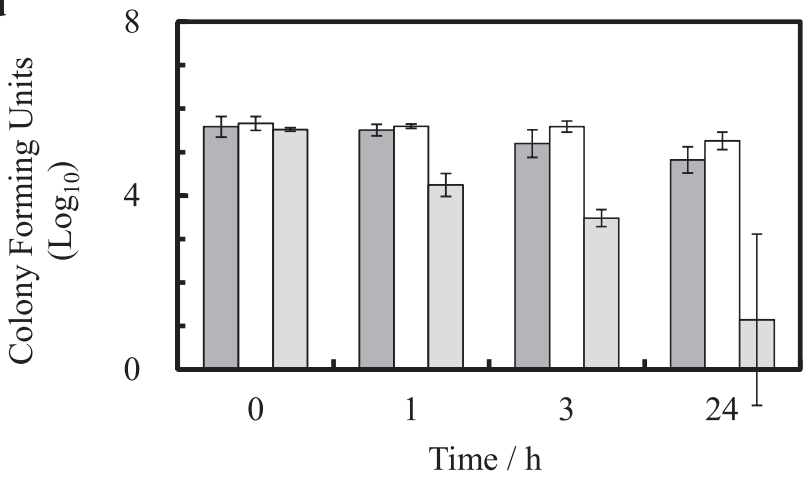

Fig. 4 Bactericidal properties of fatty acid Ca salts: (a) C16:1 fatty acid Ca salt, (b) C12:0 fatty acid $\mathrm{Ca}$ salt, (c) C16:0 fatty acid Ca salt, and (d) C18:1 fatty acid $\mathrm{Ca}$ salt.

explain why C16:1 fatty acid Ca salt is so specific on the bactericidal activity would help developing functional new cosmetic ingredients.

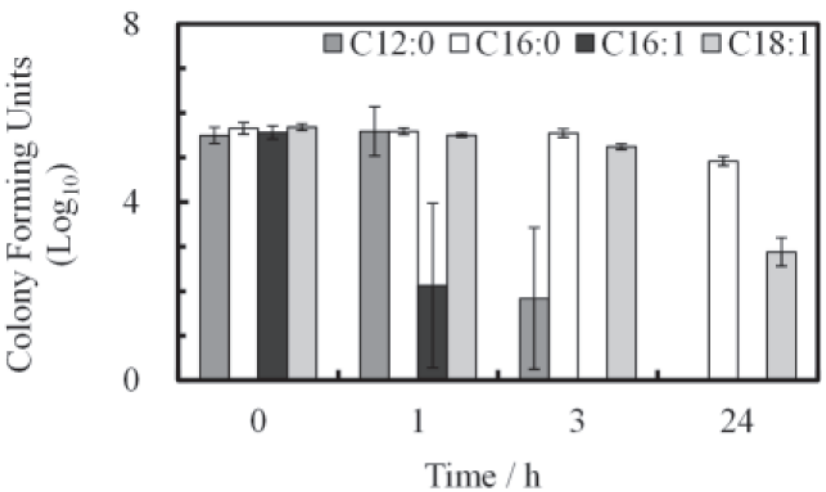

Fig. 5 Bactericidal properties of free fatty acids against P. acnes.

\section{ACKNOWLEDGMENT}

This work was partially supported by a Grant-in-Aid for Scientific Research (C) (No. 22540417) from the Ministry of Education, Culture, Sports, Science and Technology, Japan (MEXT).

\section{References}

1) Kaijser, A.; Dutta, P.; Savage, G. Oxidative stability and lipid composition of macadamia nuts grown in New Zealand. Food Chem. 71, 67-70(2000).

2) Parcerisa, J.; Boatella, J.; Codony, R.; Rafecas, M.; Castellote, A. I.; Romero, A. Comparison of fatty acid and triacylglycerol compositions of different hazelnut varieties (Corylus auellana L.) cultivated in Catalonia (Spain). J. Agric. Food Chem. 43, 13-16 (1995).

3) Yang, B.; Kallio, H. P. Fatty acid composition of lipids in Sea Buckthorn (Hippophaë rhamnoides L.) Berries of different origins. J. Agric. Food Chem. 49, 19391947 (2001).

4) Peter, M.; Elias, M. D. Epidermal lipids, barrier function, and desquamation. J. Invest. Dermat. 80, 44-49 (1983).

5) Ouattara, B.; Simard, R. E.; Holley, R. A.; Piette, G. J. P.; Bégin, A. Antibacterial activity of selected fatty acids and essential oils against six meat spoilage organisms. Int. J. Food Microbiol. 37, 155-162 (1997).

6) Bergsson, G.; Steingrímsson, Ó.; Thormar, H. In vitro susceptibilities of Neisseria gonorrhoeae to fatty acids and monoglycerides. Antimicrob. Agents Chemother. 43, 2790-2792(1999).

7) Wille, J. J.; Kydonieus, A. Palmitoleic acid isomer (C16:1 $\Delta 6)$ in human skin sebum is effective against gram-positive bacteria. Skin Pharmacol. Appl. Skin Physiol. 16, 176-187 (2003).

8) Bergsson, G.; Steingrímsson, Ó.; Thormar, H. Bactericidal effects of fatty acids and monoglycerides on $\mathrm{He}$ licobacter pylori. Int. J. Antimicrobial. Agents 20, 


\section{Y. Yamamoto, Y. Kawamura, Y. Yamazaki et al.}

258-262 (2002).

9) Somerville, D. A. The effect of age on the normal bacterial flora of the skin. Br. J. Dermatol. 81, 14-22 (1969).

10) Somerville, D. A. The normal flora of the skin in different age groups. Br. J. Dermatol. 81, 248-258(1969).

11) Poulenat, G.; Sentenac, S.; Mouloungui, Z. Double decomposition reactions for the production of alkaline and alkaline-earth oleic soaps under salting-out conditions. Ind. Eng. Chem. Res. 43, 1574-1579(2004).

12) Yoke, J. T. The solubility of calcium soap. J. Phys. Chem. 62, 753-755 (1958).

13) Matijević, E.; Leja, J.; Nemeth, R. Precipitation phenomena of heavy metal soaps in aqueous solutions : I. Calcium Oleate. J. Colloid Interface Sci. 22, 419-429 (1966).

14) Takehara, M. Properties and applications of amino acid based surfactants. Colloids Surf. 38, 149-167(1989).

15) Nonomura, Y.; Kurita, K.; Kashimoto, A,; Hotta, H.; Kaneko, Y.; Iitaka, K. The internal structure and tribology of calcium lauroyl taurate. Chem. Lett. 32, 216217 (2002).

16) Nonomura, Y.; Kurita, K.; Kashimoto, A.; Hotta, H.; Suzuki, T.; Kaneko, Y.; Iitaka, K. The crystal structure and tribology of a novel organic crystalline powder: the mechanism of lubricity. Bull. Chem. Soc. Jpn. 75, 2305-2308 (2002).

17) Bojar, R. A.; Holland, K. T. Acne and propionibacterium acnes. Clinics Dermatol. 22, 375379 (2004).

18) Lina, G.; Piémont, Y.; Godail-Gamot, F.; Bes, M.; Peter, M.-O.; Gauduchon, V.; Vandenesch, F.; Etienne; J. Involvement of Panton-Valentine Leukocidin-Producing Staphylococcus aureus in primary skin infections and pneumonia. Clin. Infect. Diseases 29, 1128-1132 (1999).

19) Ralston, A. W.; Hoerr, C. W. The solubilities of the normal saturated fatty acids. J. Org. Chem. 7, 546-555 (1942).

20) Stulnig, T. M.; Huber, J.; Leitinger, N.; Imre, E. M.; Angelisová, N. P.; Waldhäusl, W. Polyunsaturated eicosa- pentaenoic acid displaces proteins from membrane rafts by altering raft lipid composition. J. Biol. Chem. 276, 37335-37340 (2001).

21) Seidel, V.; Taylo, P. W. In vitro activity of extracts and constituents of Pelagonium against rapidly growing mycobacteria. Int. J. Antimicrob. Agents 23, 613-619 (2004).

22) Kuramitsu, K.; Nomura, T.; Nomura, S.; Maeno, T.; Nonomura, Y. Friction evaluation system with a human finger model. Chem. Lett. 42, 284-285 (2013).

23) Vold, R. D.; Smith, T. D. An X-ray diffraction study of calcium stearate monohydrate-cetane systems. J. Am. Chem. Soc. 73, 2006-2012(1951).

24) Gaenier, P.; Gregore, P. Polymorphism of crystalline phases of calcium stearate. J. Materials Sci. 23, 32253231 (1988).

25) Bagg, J.; Abramson, M. B.; Fichman, M.; Haber, M. D.; Gregor, H. P. Composition of stearic acid monolayers from calcium-containing substrates. J. Am. Chem. Soc. 86, 2759-2763 (1964).

26) Matsubara, A.; Matuura, R.; Kimizuka, H. A study of the interaction between the stearic acid monolayer and the calcium ions by the radiotracer method. Bull. Chem. Soc. Jpn. 38, 369-373(1965).

27) Greenway, D. R. A.; Dyke, K. G. H. Mechanism of the inhibitory action of linoleic acid on the growth of Staphylococcus aureus. J. Gen. Microbiol. 115, 233245 (1979).

28) Chamberlain, N. R.; Mehrtens, B. G.; Xiong, Z.; Kapral, F. A.; Boardman, J. L.; Rearick, J. I. Correlation of carotenoid production, decreased membrane fluidity, and resistance to oleic acid killing in Staphylococcus aureus 18Z. Infect. Immun. 59, 4332-4337(1991).

29) Hansch, C.; Dunn, W. J. Linear relationships between lipophilic character and biological activity of drugs. $J$. Pharm. Sci. 61, 1-19 (1972).

30) Togashi, N.; Shiraishi, A.; Nishizaka, M.; Matsuoka, K.; Endo, K.; Hamashima, H.; Inoue, Y. Antibacterial activity of long-chain fatty alcohols against Staphylococcus aureus. Molecules 12, 139-148(2007). 